\title{
Study of Morphological Patterns of Leprosy in a Rural Setup
}

\author{
Sweety Haribhau Gulhane ${ }^{1}$, Keshao Madhukar Hiwale², Arvind Shridhar Bhake³, Sunita Vagha ${ }^{4}$, Samarth Shukla ${ }^{5}$ \\ ${ }^{1}$ Department of Pathology, Jawaharlal Nehru Medical College, Acharya Vinoba Bhave Rural Hospital, Sawangi \\ (Meghe) Wardha, Maharashtra, India. ${ }^{2}$ Department of Pathology, Jawaharlal Nehru Medical College, Acharya \\ Vinoba Bhave Rural Hospital, Sawangi (Meghe) Wardha, Maharashtra, India. ${ }^{3}$ Department of Pathology, \\ Jawaharlal Nehru Medical College, Acharya Vinoba Bhave Rural Hospital, Sawangi (Meghe) Wardha, \\ Maharashtra, India. ${ }^{4}$ Department of Pathology, Jawaharlal Nehru Medical College, Acharya Vinoba Bhave Rural \\ Hospital, Sawangi (Meghe) Wardha, Maharashtra, India. ${ }^{5}$ Department of Pathology, Jawaharlal Nehru Medical \\ College, Acharya Vinoba Bhave Rural Hospital, Sawangi (Meghe) Wardha, Maharashtra, India.
}

\section{ABSTRACT}

\section{BACKGROUND}

Leprosy is a chronic disease of ancient world and is still afflicting patients in many parts of world mainly Asia and Africa. Leprosy is one of the most dreaded diseases of humankind. We wanted to study the various microscopic patterns and subtypes of Leprosy. We also wanted to study the Bacterial Index in the region of Sawangi, Meghe.

\section{METHODS}

80 skin biopsies after adequate fixation in $10 \%$ of formalin, were routinely processed and were stained with $\mathrm{H}$ and E, Fite-Faraco stain and Modified Rapid Acid-Fast Bacilli (MRAFB staining) method, were studied microscopically and bacterial index was calculated.

\section{RESULTS}

A total of 80 skin biopsies were obtained from patients of department of dermatology over a period of two years from 2017 to 2019. Among them Lepromatous leprosy were 43 cases, Tuberculoid leprosy were 23 cases, Borderline lepromatous leprosy were 09 cases, Borderline tuberculoid leprosy were 03 cases, histoid leprosy were 01 case and ENL were 01 case. With an age range of 6 - 85 years, majority were in 31-40 years of age group, with male to female ratio of 2.47:1. LL was the most common type of leprosy (53.75\%).

\section{CONCLUSIONS}

Accurate diagnosis of leprosy purely on clinical grounds is extremely difficult. Hence, there can be false positive and false negative diagnosis. Since histopathology is confirmatory, with application of Fite-Faraco and MRAFB staining it can also evaluate the bacterial load. Hence in all suspected cases of leprosy, histopathology along with Fite-Faraco and MRAFB staining should compulsorily be done.

\section{KEY WORDS}

Acid Fast Bacilli, Bacterial Index, Fite-Faraco Stain, MRAFB Staining, Ridley-Jopling Classification
Corresponding Author: Dr. Sweety Haribhau Gulhane, Department of Pathology, Jawaharlal Nehru Medical College, Archarya Vinoba Bhave Rural Hospital, Sawangi (Meghe) Wardha, Maharashtra, India.

E-mail: sweetygulhane@gmail.com

DOI: $10.14260 /$ jemds/2020/134

Financial or Other Competing Interests: None.

How to Cite This Article:

Gulhane SH, Hiwale KM, Bhake AS, et al Study of morphological patterns of leprosy in a rural setup. J. Evolution Med. Dent. Sci. 2020;9(09):603-607, DOI: 10.14260/jemds/2020/134

Submission 26-11-2019, Peer Review 03-02-2020, Acceptance 11-02-2020, Published 02-03-2020.

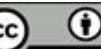




\section{BACKGROUND}

Leprosy is one of the most dreaded diseases of mankind. ${ }^{1}$ Leprosy is confined mainly to the underdeveloped areas of the tropics. The most affected areas are South and Southeast Asia and Brazil. ${ }^{2}$ Official data for the year 2017 of leprosy were received from 159 countries from all WHO Regions. The prevalence was 0.25 per 10,000 population means $1,92,173$ leprosy cases. The incidence was 2.8 per 100000 population reported means 2,10,671 leprosy cases. Out of this 6\% $(12,189$ cases) are presented with grade- 2 disabilities (G2D), in which 238 children are reported. There is slight decrease in new case detection from 2,14,783 in 2016 to 2,10,942 in $2017 .^{3}$

India has the greatest prevalence of leprosy. ${ }^{2}$ In India leprosy is present in all states and territories, with marked regional variations. ${ }^{2}$ Bihar accounts for highest incidence followed by Uttar Pradesh and Maharashtra. ${ }^{4}$ In 2005 India, was declared leprosy free having incidence of below one per 10,000 population of leprosy. ${ }^{4}$ In India, Maharashtra has the 3rd highest leprosy population. ${ }^{4}$ In Maharashtra 16,065 new leprosy cases were recorded in 2017-2018, out of this 10.11 $\%$ were children. ${ }^{4}$ of the total leprosy patients in Maharashtra, $53 \%$ (8,601 cases) are multibacillary and $47 \%$ $(7,264$ cases $)$ are paucibacillary. ${ }^{4}$ In children the rate of leprosy is reduced slightly from $11 \%$ in $2016-17$ to $10.11 \%$ in 2017-18. In 2014-15, 2,045 children and in 2015-16, 1,764 children were diagnosed with the disease. ${ }^{4}$ Leprosy is more prevalent in Vidarbha as compared to other districts of Maharashtra. ${ }^{5}$ Amravati, Buldhana, Chandrapur, Gadchiroli, Gondia, and Wardha districts of Vidarbha have high prevalence of leprosy. ${ }^{5}$ In Gadchiroli high prevalance rate of leprosy is found which is 4.5 in 10,000 population. ${ }^{5}$ Annual new case detection rate of Gadchiroli and Chandrapur districts is 50 in $1,00,000$ population. ${ }^{5}$ As the incidence and prevalence is more in this region where our Rural Institute is established therefore the study is planned to see histomorphological patterns, bacterial index as well as to categorize the various types of Leprosy.

\section{METHODS}

This is a cross sectional study carried out in the Department of Pathology in Rural hospital, after obtaining Institutional Ethics Committee (DMIMS/IEC/2017-18/6722) approval. All clinically suspected cases of leprosy from dermatology outpatient department and histopathologically diagnosed cases were included in the study.

\begin{tabular}{|c|c|c|}
\hline Modified Rapid Acid-Fast Bacilli Method & Number of Cases & $\mathbf{\%}$ \\
\hline Positive & 27 & $33.75 \%$ \\
\hline Negative & 53 & $66.25 \%$ \\
\hline Total & $\mathbf{8 0}$ & $\mathbf{1 0 0 \%}$ \\
\hline $\begin{array}{c}\text { Table 1. Presence of AFB by Modified Rapid Acid Fast Bacilli } \\
\text { Method in Present Study }\end{array}$ \\
\hline
\end{tabular}

All patients with different clinical spectrum of leprosy were included in the study. Clinical examination was carried out and leprosy cases were classified clinically according to Ridley- Jopling scale.6,7
Ridley- Jopling Classification (1966) ${ }^{6,7}$

1. Tuberculoid leprosy (TT)

2. Borderline tuberculoid leprosy (BT)

3. Mid-borderline leprosy (BB)

4. Borderline lepromatous leprosy (BL)

5. Lepromatous leprosy (LL)

Ridley Jopling appreciated the fact that leprosy is a complex disease and bacteriological, immunological, histopathological and clinical factors are interconnected and all this 4 criteria should be considered for classification purpose. Hence Ridley Jopling classification can be considered a superior and more acceptable. In Ridley Jopling classification we have 5 groups- Tuberculoid (TT), Lepromatous (LL) as two ends of the spectrum. In between these two polar forms there is a third category of immunologically unstable patient known as Borderline tuberculoid (BT), mid-borderline (BB), and Borderline lepromatous (BL).

Here it is noteworthy that BB i.e. mid-borderline is the most unstable form immunologically. If the patient's immune status improves than BB will be converted to BT. If the immunological status deteriorates then $\mathrm{BB}$ will be converted to BL.

Thus, we get a spectrum as-

1. Tuberculoid (TT) - Immunologically stable

2. Borderline (BT,BB,BL) -In TT we have good immunological status and if this status for whatever reason goes down then we get $\mathrm{BT}, \mathrm{BB}, \mathrm{BL}, \mathrm{LL}$.

3. Lepromatous leprosy (LL) - Here the patient's immune status is fully collapsed.

4. An advantage of Ridley Jopling classification is it is easier to understand as well as it helps us to understand the variations in disease in better way.

Skin biopsies from all patients from active lesions were taken and then biopsies were sent to the histopathology section of Department of Pathology. In histopathology section of Department of Pathology, staining was carried out by Haematoxylin and Eosin stain ${ }^{8}$ and special staining by FiteFaraco, ${ }^{9}$ Modified Rapid Acid-Fast Bacilli Method ${ }^{10}$ for identification of Mycobacterium leprae and Bacterial index ${ }^{11}$ were calculated.

\section{Exclusion Criteria}

1. Inadequate and poorly preserved skin biopsies.

2. Biopsies which will not reveal histology of leprosy.

\section{Sample Size}

Sample size at the required absolute precision level for specificity can be calculated by Buderer's formula:

Sample size (n) based on specificity=

$$
\frac{Z_{1-\alpha / 2}^{2} \times S_{P} \times\left(1-S_{P}\right)}{L^{2} \times(1-\text { Prevalance })}
$$

Where, $\mathrm{n}=$ required sample size, $\mathrm{S}=$ anticipated Specificity $=$ $72 \%=0.72, \alpha=$ size of the critical region $(1-\alpha$ is the confidence level) $0.05, \mathrm{z}_{1-\alpha / 2}=$ standard normal deviate 
corresponding to the specified size of the critical region $(\alpha)=$ 1.96, $\mathrm{L}=$ absolute precision desired on either side (half-width of the confidence interval) of $=0.05, \mathrm{P}=$ Prevalence $=3.33 \%=$ 0.033

$$
N=\frac{1.96^{2} * 0.72 *(1-0.72)}{0.05^{2} *(1-0.033)}
$$

$=80.08$

$=80$ patients needed

\section{Statistical Analysis}

The data was collected, compiled and analysed. The quantitative and qualitative variables were expressed in terms of percentages.

\section{RESULTS}

\section{Patient Characteristics}

In the present study, majority of the study subjects were in the age group of 31-40 and 41 to 50 years followed by 51 to 60 years and 21 to 30 years with lowest age of 6 years and highest age of 85 years. In the present study, most of the patients affected were males $57 / 80$ cases (i.e. $71.25 \%$ ). Female patients were $23 / 80$ (i.e. $28.75 \%$ ) found to be affected.

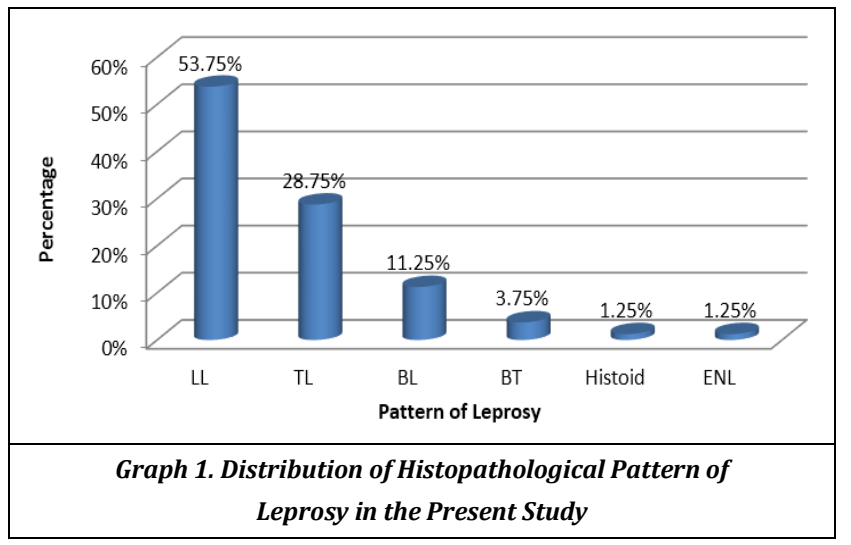

In the present study, based on the Histopathological diagnosis, $53.75 \%$ were LL type cases followed by TT type accounting for $28.75 \%, 11.25 \%$ were BL type $3.75 \%$ were BT type, $1.25 \%$ each were histoid leprosy and ENL, and no case of BB was diagnosed in our study.

\section{Acid Fast Bacilli by Fite-Faraco Staining Method}

Out of 80 cases which were diagnosed as leprosy, 23 cases of tuberculoid leprosy and 03 cases of Borderline tuberculoid leprosy were negative by Fite-Faraco method. Out of 43 cases of Lepromatous leprosy, 25 cases were Fite-Faraco positive and 18 cases were Fite-Faraco negative. Out of 09 cases of Borderline lepromatous leprosy, 2 cases were Fite-Faraco positive and 7 cases were Fite-Faraco negative. A single case of HL and ENL was diagnosed and both was Fite-Faraco positive.

\section{AFB by Modified Rapid Acid-Fast Bacilli Staining Method} Out of 80 cases which were diagnosed as leprosy, 23 cases of tuberculoid leprosy and 03 cases of Borderline tuberculoid leprosy were negative by Modified Acid Fast Bacilli method. Out of 43 cases of Lepromatous leprosy, 23 cases were found positive for bacilli by Modified Acid Fast Bacilli Staining Method and 20 cases were found negative for bacilli by Modified Acid Fast Bacilli Staining Method. Out of 09 cases of Borderline lepromatous leprosy, 2 cases were found positive for bacilli by Modified Acid Fast Bacilli Staining Method and 7 cases were found negative for bacilli by Modified Acid Fast Bacilli Staining Method. A single case of HL and ENL was diagnosed which was found positive for bacilli by Modified Acid Fast Bacilli positive.

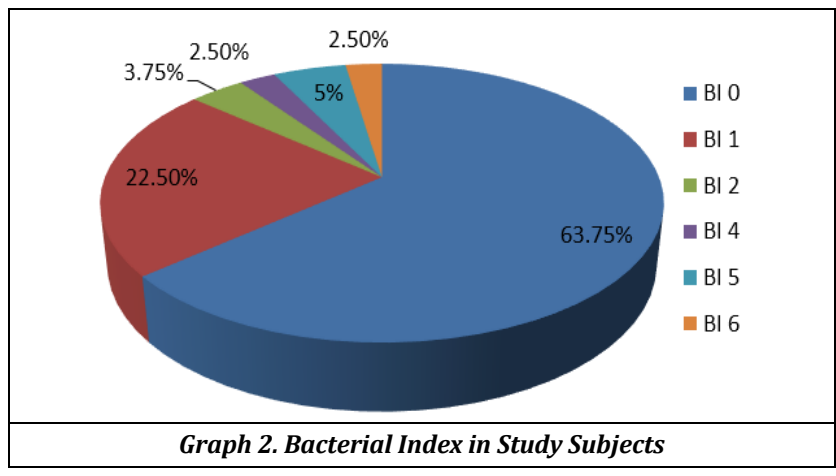

In present study out of 80 cases which were diagnosed as leprosy, 29 cases showed presence of acid fast bacilli with BI 1 in $18(22.5 \%)$ cases, BI 2 in $03(3.75 \%)$ cases, BI 4 in 02 $(2.5 \%)$ cases, BI 5 in $04(5 \%)$ cases, BI 6 IN $02(2.5 \%)$ cases. In our study rest 51 cases (i.e. $63.75 \%$ ) showed absence of acid fast bacilli with BI of 0 . No case with BI 3 was observed in the present study.

\section{DISCUSSION}

In present study we have attempted to classify various types of leprosy by using Ridley Jopling Classification and also the application of Fite-Faraco staining and Modified Rapid Acid Fast Bacilli staining technique. The present study was conducted in the department of Pathology, AVBRH, Sawangi (M), Wardha.

\section{Subject Characteristics}

In present study we observed that the peak incidence of leprosy occurred in 31-40 years which correlates well with the study of Sehgal et al,12 Anuja Sharma et al,13 Vora RV et al, ${ }^{14}$ Tekwani $\mathrm{D}$ and Joshi $\mathrm{R}$ et al. ${ }^{9}$ In the present study the lowest age of the study subject was 6 years and highest age of 85 years. Majority of the study subjects were in the age group of 31 to 40 years followed by 41 to 50 years and 51 to 60 years. Most of the studies showed the peak incidence in 21 to 30 years and 21 to 40 years. Hence the minimum number of cases observed in the present study was in the 1st decade and it is in full agreement with Fauziahkurdi et al,15 Tekwani D and Joshi R et al.11

In the present study our observation for distribution of leprosy cases in both sexes is in concordance with other studies like, Fakeha Firdous DP et al,16 Kumar A et al,17 Badhan R et al, ${ }^{18}$ Mehta. B et al, ${ }^{19}$ Premanshu Bhushan et al, ${ }^{20}$ Veena Shivamurthy et al. ${ }^{21}$ In the present study our 
observations shows that $57 / 80$ i.e. $71.25 \%$ were males and $23 / 80$ i.e. $28.75 \%$ were females. Thus males show higher predilection for leprosy as compared to females and $\mathrm{M}$ : F ratio is 2.47:1 which is in concordance with other studies like Fakeha Firdous DP et al, ${ }^{16}$ Veena Shivamurthy et al. ${ }^{21}$ The disease more commonly occurs usually in males because of more opportunities for exposure to infection which can be due to job related mobility.

\begin{tabular}{|c|c|c|c|c|c|c|c|c|c|}
\hline 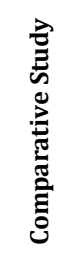 & 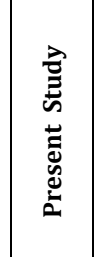 & 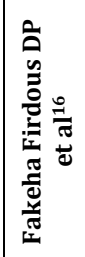 & 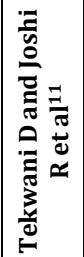 & 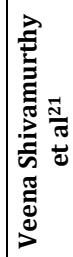 & 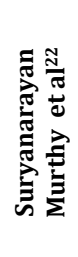 & $\begin{array}{l}\frac{N}{\pi} \\
\frac{N}{0} \\
0 \\
0 \\
0 \\
0 \\
0 \\
\end{array}$ & 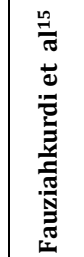 & 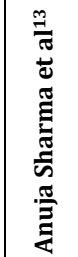 & 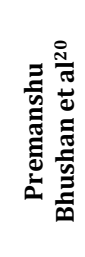 \\
\hline Year & 2019 & 2018 & \begin{tabular}{|l|}
2017 \\
\end{tabular} & \begin{tabular}{|l|}
2017 \\
\end{tabular} & 2015 & \begin{tabular}{|l|}
2014 \\
\end{tabular} & 2011 & \begin{tabular}{|l|}
2008 \\
\end{tabular} & 2008 \\
\hline $\begin{array}{l}\text { No. of } \\
\text { Cases } \\
\end{array}$ & 80 & 116 & 135 & 145 & 100 & 50 & 85 & 270 & 141 \\
\hline TT & $28.75 \%$ & $9.4 \%$ & $19.25 \%$ & $1.5 \%$ & $5 \%$ & $10 \%$ & $21.42 \%$ & $\begin{array}{l}7.69 \% \\
\end{array}$ & $2.12 \%$ \\
\hline BT & $3.75 \%$ & $16.3 \%$ & $57.77 \%$ & $72.5 \%$ & $55 \%$ & \begin{tabular}{|l|}
$40 \%$ \\
\end{tabular} & $14.28 \%$ & & $58.86 \%$ \\
\hline BB & $\mathbf{0 0} \%$ & $00 \%$ & \begin{tabular}{|l|l|}
$0.74 \%$ \\
\end{tabular} & $2.5 \%$ & $2 \%$ & \begin{tabular}{|l|}
$00 \%$ \\
\end{tabular} & $23.21 \%$ & $74.09 \%$ & $8.51 \%$ \\
\hline $\mathrm{BL}$ & $11.25 \%$ & $15.5 \%$ & $14.81 \%$ & $10.5 \%$ & $8 \%$ & $12.5 \%$ & $16.07 \%$ & & $16.31 \%$ \\
\hline LL & $53.75 \%$ & $52.5 \%$ & $5.18 \%$ & $5.5 \%$ & $29 \%$ & \begin{tabular}{|l|}
$10 \%$ \\
\end{tabular} & $23.2 \%$ & $11.74 \%$ & $8.51 \%$ \\
\hline IL & $00 \%$ & $00 \%$ & \begin{tabular}{|l|}
$00 \%$ \\
\end{tabular} & $7.5 \%$ & $1 \%$ & $27.5 \%$ & $1.78 \%$ & $6.48 \%$ & $5.67 \%$ \\
\hline $\mathrm{HL}$ & $1.25 \%$ & $00 \%$ & $2.22 \%$ & $00 \%$ & $00 \%$ & \begin{tabular}{|l|}
$00 \%$ \\
\end{tabular} & $00 \%$ & $00 \%$ & $00 \%$ \\
\hline ENL & $1.25 \%$ & $\begin{array}{l}6.03 \% \\
\end{array}$ & $00 \%$ & $00 \%$ & $00 \%$ & \begin{tabular}{|l|}
$00 \%$ \\
\end{tabular} & $00 \%$ & $00 \%$ & $00 \%$ \\
\hline
\end{tabular}

In the present study out of 80 cases the commonest histopathological subtype was LL accounting for $43 / 80$ cases i.e. $53.75 \%$ which is in concordance with study done by Fakeha Firdous DP et al ${ }^{16}$ followed by TT being $23 / 80$ i.e. $28.75 \%$, BL cases were $09 / 80$ i.e. $11.25 \%$, BT which were $03 / 80$ i.e. $3.75 \%, 1 / 80$ i.e. $1.25 \%$ case of HL and $1 / 80$ i.e. $1.25 \%$ case of ENL and no case of BB was found which is in concordance with study done by AC Lobo et al ${ }^{23}$. Borderline group is unstable as it can shift to either pole of the spectrum i.e. Tuberculoid and Lepromatous pole. In present study $1 / 80$ case i.e. $1.25 \%$ HL was observed which is in concordance with Tekwani D and Joshi R et al. ${ }^{11}$

\begin{tabular}{|c|c|c|c|}
\hline $\begin{array}{c}\text { Comparative } \\
\text { Study }\end{array}$ & $\begin{array}{c}\text { M. Giridhar } \\
\text { et al }^{\mathbf{2 4}}\end{array}$ & $\begin{array}{c}\text { M. Suryanarayana } \\
\text { Murthy et al } \mathbf{l}^{\mathbf{2 2}}\end{array}$ & $\begin{array}{c}\text { Present } \\
\text { Study }\end{array}$ \\
\hline Year & 2012 & 2015 & 2019 \\
\hline No. of cases & 100 & 100 & 80 \\
\hline $\begin{array}{c}\text { AFB Positive } \\
\text { (Fite-Faraco Method) }\end{array}$ & $56.13 \%$ & $25 \%$ & $36.25 \%$ \\
\hline $\begin{array}{c}\text { AFB Negative } \\
\text { (Fite-Faraco Method) }\end{array}$ & $43.87 \%$ & $75 \%$ & $63.75 \%$ \\
\hline Table 3. A Comparative Study Based on Presence or Absence of \\
AFB by Fite-Faraco Staining Method \\
\hline
\end{tabular}

In the present study out of 80 cases of leprosy, stained with Fite-Faraco stain 29 i.e. $36.25 \%$ cases showed presence of acid fast bacilli and 51 i.e. $63.75 \%$ cases lacked acid fast bacilli which is in concordance with study done by $\mathrm{M}$. Giridhar et $\mathrm{al}^{22}$ observed 55 i.e. $56.13 \%$ cases showed presence of acid fast bacilli and 43 i.e. $43.87 \%$ cases lacked acid fast bacilli similarly M. Suryanarayana Murthy et al 20 observed that 25 i.e. $25 \%$ cases showed presence of acid fast bacilli and 75 i.e. $75 \%$ cases lacked acid fast bacilli. In the present study 27 i.e. $33.75 \%$ cases showed presence of acid fast bacilli and 53 i.e. $66.25 \%$ cases lacked acid fast bacilli when stained by MRAFB method.
Out of 43 cases of LL 18 were negative for bacilli by FiteFaraco method while 20 were negative for bacilli by MRAFB method as they were on treatment. Out of 09 cases of BL 07 case were negative for bacilli by both Fite-Faraco and MRAFB method as they were on treatment.

\section{CONCLUSIONS}

Accurate diagnosis of leprosy purely on clinical grounds is extremely difficult. Hence, there can be false positive and false negative diagnosis. Since histopathology is confirmatory, with application of Fite-Faraco and MRAFB staining it can also evaluate the bacterial load. Hence in all suspected cases of leprosy, histopathology along with FiteFaraco and MRAFB staining should compulsorily be done.

\section{REFERENCES}

[1] Baveja CP. Text book of Microbiology. $6^{\text {th }}$ edn. Arya Publication 2018: p. 363.

[2] Ananathanarayan R. Ananthnarayan and Paniker's. Text book of Microbiology. $8^{\text {th }}$ edn. Universities Press 2009: p. 366-7.

[3] World Health Organization South-east Asia, Global leprosy programme, Epidemiology, 2017. http://www.searo.who.int/entity/global_leprosy_progra mme/epidemiology/en/.

[4] Tabassum B. Maharashtra: 16,065 leprosy cases in 201718, state government plans two drive. May 2018. https://indianexpress.com/article/cities/mumbai/maha rashtra-16065-leprosy-cases-in-18-state-governmentplans-two-screening-drives-5157830/.

[5] Manasi D. Vidarbha has a higher burden of leprosy in Maharashtra: study, August 4, 2017. http://www.mymedicalmantra.com/vidarbha-hasmore-burden-of-leprosy-in-maharashtra-study/.

[6] Ridley DS, Jopling WH. A classification of leprosy for research purposes. Lepr Rev 1962;33:119-28.

[7] Ridley OS, Jopling WH. A classification of leprosy according to immunity - a five group system. Int J Lepr Other Mycobact Dis 1966;34(3):255-73.

[8] Bancroft JD, Suvarna SK, Layton C. Bancroft's Theory and practice of histological techniques. $7^{\text {th }}$ edn. Elsevier, Churchill Livingstone 2012: p. 173-9.

[9] Job CK, Chacko CJ. A modification of Fite's stain for demonstration of M. Leprae in tissue sections. Indian Journal of Leprosy 1986;58(1):17-8.

[10] Nayak SV, Shivarudrappa AS, Nagarajappa AH, et al. Role of modified rapid AFB method in histopathological sections of Hansen's disease. Indian Journal of Dermatology Venereology and Leprology 2003;69(2):173-4.

[11] Tekwani D, Joshi R, Joshi S. Clinico-histopathological correlative study of leprosy at a rural hospital. J Med Sci \& Clin Res 2017;5(5):22532-41.

[12] Sehgal VN, Ghorpade A, Saha K. Urban leprosy--an appraisal from northern India. Leprosy Review 1984;55(2):159-66. 
[13] Sharma A, Sharma RK, Goswsami KC, et al. Clinicohistopathological correlation in leprosy. JK Science 2008;10(3):120-3.

[14] Vora RV, Diwan NG, Patel NH, et al. Clinicohistopathological correlation in leprosy: a study at a rural based tertiary care centre, Gujarat. Indian J Clinical \& Experimental Dermatology 2016;2(1):23-6.

[15] Kurdi FN, Pamudji R, Maulani H, et al. Correlation of histopathological skin biopsies with clinical diagnosis in leprosy. Folia Medica Indonesiana 2011;47(1):30-5.

[16] Firdous F, Sridevi P, Majeed A, et al. To assess the burden of and trends of Hansens disease-mainly by assessing the histomorphological spectrum and clinicopathological correlation, at a tertiary care hospital in Telangana State, India. World J Pharm \& Med Res 2018;4(8):148-54.

[17] Kumar A, Negi SR, Vaishnav K. A study of Clinicohistopathological correlation of leprosy in a tertiary care hospital in western district of Rajasthan. J Res in Med Dent Sci 2014;2(3):43-8.

[18] Badhan R, Kundal RK, Raj RT, et al. A clinicopathological correlation study of leprosy in a tertiary care teaching institute in Northwest Punjab, India. Am J Med Sci Med 2014;2(5):99-108.
[19] Mehta B, Desai N, Khar S. Clinic pathological correlation in leprosy. The Internet Journal of Dermatology 2012;9(1)

[20] Bhushan P, Sardana K, Koranne RV, et al. Diagnosing multibacillary leprosy: a comparative evaluation of diagnostic accuracy of slit-skin smear, bacterial index of granuloma and WHO operational classification. Indian Journal of Dermatology, Venereology, Leprology 2008;74(4):322-6.

[21] Shivamurthy V, Gurubasavaraj H, Shashikala PS, et al. Histomorphological study of leprosy. African Journal of Medical and Health Sciences 2013;12(2):68-73.

[22] Murthy MS, Duara G, Viswanath KK, et al. Clinical and histopathological correlation in Hansen's disease. Journal of Evolution of Medical and Dental Sciences 2015;4(35):6081-6.

[23] Lobo AC, Pai RR, Gautam K, et al. Correlation of clinicopathological classification of Hansen's Disease in a South Indian City. Indian J Lepr 2014;86(4):147-54.

[24] Giridhar M, Arora G, Lajpal K, et al. Clinicohistopathological concordance in leprosy-a clinical, histopathological and bacteriological study of 100 cases. Indian J Lepr 2012;84(3):217-25. 